\title{
Impact of the Deepwater Horizon oil spill on loggerhead turtle Caretta caretta nest densities in northwest Florida
}

\author{
Ann Marie Lauritsen ${ }^{1, *}$, Philip M. Dixon ${ }^{2}$, Dave Cacela ${ }^{3}$, Beth Brost ${ }^{4}$, Robert Hardy ${ }^{4}$, \\ Sandra L. MacPherson ${ }^{1}$, Anne Meylan ${ }^{4}$, Bryan P. Wallace ${ }^{3,5}$, Blair Witherington ${ }^{6}$ \\ ${ }^{1}$ US Fish and Wildlife Service, Jacksonville, Florida 32256, USA \\ ${ }^{2}$ Iowa State University, Ames, Iowa 50011, USA \\ ${ }^{3}$ Abt Associates Inc., Boulder, Colorado 80302, USA \\ ${ }^{4}$ Florida Fish and Wildlife Conservation Commission, St. Petersburg, Florida 33701, USA \\ ${ }^{5}$ Duke University Marine Lab, Beaufort, North Carolina 28516, USA \\ ${ }^{6}$ Disney's Animals, Science and Environment, Lake Buena Vista, Florida 32830, USA
}

\begin{abstract}
The 2010 Deepwater Horizon (DWH) oil spill and associated response activities overlapped with habitats for multiple life stages of federally protected sea turtles in the northern Gulf of Mexico. Although most assessment efforts focused on documenting the presence, abundance, and exposure of sea turtles to DWH oil in marine habitats, oil also washed ashore on sand beaches used by nesting turtles, specifically in NW Florida and Alabama, USA. In addition, extensive and highly mechanized beach cleanup efforts were conducted in NW Florida as well as Alabama, Louisiana, and Mississippi. Thus, the DWH oil spill negatively affected sea turtle nesting directly (e.g. adverse effects of oil exposure) and indirectly (e.g. beach cleanup activities deterring nesting) in several ways. In this study, we used a before-after, control-impact statistical modeling approach to examine long-term (1997-2012) historical records of loggerhead turtle (Caretta caretta) nest densities in 2 segments of the Florida Gulf coastline, one that was heavily affected by the oil spill (NW Florida) and one that was relatively unaffected (SW Florida). Loggerhead nest densities on NW Florida beaches in 2010 were reduced by $43.7 \%$ (95\% confidence interval: $10-65 \%$ ) relative to expected nesting rates in the absence of DWH oil and cleanup efforts. When we applied this reduction to all nesting habitat in NW Florida, this equated to a loss of approximately 251 unrealized nests from the 2010 nesting season - a loss we attribute to direct (e.g. mortality) and indirect (e.g. deterrence of nesting) effects related to the DWH incident.
\end{abstract}

KEY WORDS: Caretta caretta - Deepwater Horizon oil spill · Natural Resource Damage Assessment $\cdot$ Oil spill injury $\cdot$ Sea turtle nesting

\section{INTRODUCTION}

The Deepwater Horizon (DWH) oil spill contaminated $112115 \mathrm{~km}^{2}$ of surface waters and $2100 \mathrm{~km}$ of shoreline and adversely affected a wide diversity of biotic and abiotic natural resources in the Gulf of Mexico (GoM) marine ecosystem (DWH NRDA Trustees 2016). For example, the extensive oiling overlapped with vital foraging, migratory, and nesting

*Corresponding author: AnnMarie_Lauritsen@fws.gov habitats used by different life stages of 5 sea turtle species that occur in the northern GoM: loggerheads Caretta caretta, Kemp's ridleys Lepidochelys kempii, green turtles Chelonia mydas, hawksbills Eretmochelys imbricata, and leatherbacks Dermochelys coriacea. In particular, DWH oil contaminated offshore Sargassum habitats and nesting beaches that were designated as 'critical habitat' for loggerheads under the US Endangered Species Act (ESA) in July 
2014. Consequently, sea turtles were key taxa assessed under the DWH Natural Resource Damage Assessment (NRDA) (DWH NRDA Trustees 2016). Specifically, the DWH NRDA Trustees quantified 'injuries' to sea turtles, which are defined under the US Oil Pollution Act of 1990 as 'an observable or measurable adverse change in a natural resource or impairment of a natural resource service caused by an oil spill incident' [15 CFR $§ 990.30]$. Under this definition, injuries can include mortality as well as sub-lethal effects, such as unrealized or deferred reproduction. After quantifying injuries, the NRDA also includes development and implementation of a restoration plan to compensate for the natural resource losses.

NRDA activities primarily focused on documenting presence, abundance, and exposures of different sea turtle life stages across multiple marine habitats impacted by DWH oil and associated response activities at sea (DWH NRDA Trustees 2016). However, sand beaches suitable for nesting and embryonic development are disproportionately important to sea turtle life cycles (Musick \& Limpus 1997); this warranted dedicated efforts to assess potential DWH oil effects on these habitats and the life stages that rely on them - particularly gravid adult females, their eggs, and hatchlings (DWH NRDA Trustees 2016).

Loggerheads, the primary species found on northern GoM nesting beaches, were the focus of the present study. Loggerheads in the GoM belong to the Northwest Atlantic Ocean (NWA) distinct population segment (DPS), which is listed as 'threatened' under the ESA (NMFS \& USFWS 2011). Loggerheads in the NWA DPS are further subdivided into 5 recovery units, which are management subunits that are geographically or otherwise identifiable and essential to the recovery of the loggerhead NWA DPS (NMFS \& USFWS 2008, 2011). Loggerhead nesting in the northern GoM is concentrated on beaches in NW Florida (also referred to as the Florida Panhandle) and Alabama. Loggerhead turtles nesting on these beaches belong to the Northern GoM Recovery Unit within the NWA DPS, which includes females nesting on beaches in the Florida Panhandle through Texas (NMFS \& USFWS 2008, 2011). Loggerhead females in the Northern GoM Recovery Unit are demographically distinct from other the other recovery units in the SE USA, including the Peninsular Florida Recovery Unit, based on mitochondrial DNA haplotype frequencies (Shamblin et al. 2011, 2012). The Northern GoM Recovery Unit is relatively small, with 699 nests laid annually in Florida (2005-2009), versus the larger Peninsular Florida Recovery Unit, with approximately 51520 nests laid annually (2005-
2009). However, turtles that nest in NW Florida and Alabama overlap significantly in migratory and foraging areas with loggerheads from other recovery units, including those from GoM beaches along the Florida peninsula that belong to the Peninsula Florida Recovery Unit (Hart et al. 2012, 2013, Foley et al. 2014, Hardy et al. 2014, Tucker et al. 2014). Thus, despite genetic differences between these recovery units (Shamblin et al. 2011, 2012), biological traits such as seasonal nesting phenology and annual nesting female abundance might be expected to respond similarly to widespread, broad-scale environmental conditions operating across geographic areas (Chaloupka et al. 2008, Weishampel et al. 2010, Lamont \& Fujisaki 2014).

The DWH oil spill occurred between April and September 2010 and contaminated nearshore waters and beaches in NW Florida, Alabama, Louisiana, and Mississippi, which are part of the Northern GoM Recovery Unit (Fig. 1). In addition to oiling, response activities related to beach cleanup, including mechanical removal of oiled sand and debris with heavy machinery, artificial lighting, and noise, were prevalent on these beaches during the sea turtle nesting season of 2010 (Michel et al. 2015) (Fig. 2). Anthropogenic manipulation of nesting beach habitats (e.g. coastal development, nourishment, artificial lighting) can negatively affect nesting sea turtles, and has been implicated in observed declines in nesting activity (Witherington et al. 2014, NMFS \& USFWS 2008). Thus, the DWH incident may have affected loggerhead nesting in NW Florida in 2010 through a variety of pathways and mechanisms. Our study was designed to test the hypothesis that loggerhead nesting on NW Florida beaches in 2010 was reduced relative to that expected in the absence of the spill and to quantify the magnitude of the hypothesized reduction. The possibility of an adverse effect on nesting was initially presented in an NRDA Opinion Paper (Lauritsen et al. 2012). The quantitative results reported here were used in the DWH NRDA sea turtle injury assessment (Cacela \& Dixon 2013, DWH NRDA Trustees 2016), and they are contextualized using ideas initially developed by Lauritsen et al. (2012).

\section{MATERIALS AND METHODS}

\section{Nesting data}

We used loggerhead nesting data collected as part of the Index Nesting Beach Survey (INBS) program conducted by the Florida Fish and Wildlife Conserva- 
tion Commission (2012). The INBS program has developed a long-term database of nesting activity at specific beaches, known as index beaches. The 32 INBS beaches comprise a subset of the $>200$ Statewide Nesting Beach Survey beaches, and the INBS beaches are distinguished by consistent survey effort from year to year. Briefly, the program deploys trained observers annually to a fixed set of index beaches to count and record nesting activity daily from 15 May to 31 August (109 d), which represents most of the loggerhead nesting season. Nest counts were recorded within $\sim 1-\mathrm{km}$ zones along each index beach. The datasets collected by the program have been used in statistical assessments of temporal trends in loggerhead nesting in Florida (Witherington et al. 2009).
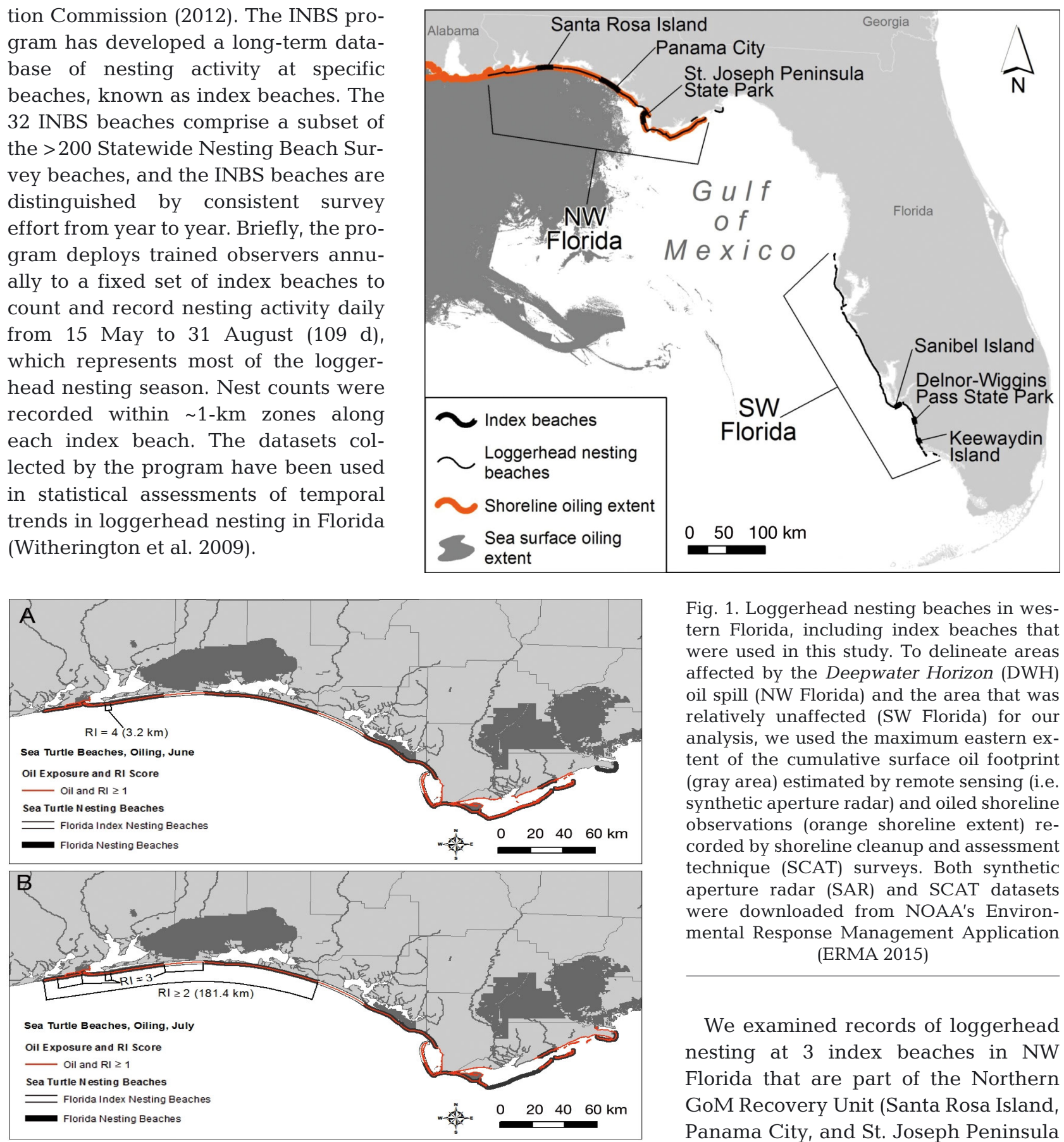

Fig. 2. DWH oil and mechanized cleanup activities (depicted by Response Injury categories; Michel et al. 2015) affected the NW Florida shoreline, including 3 index loggerhead nesting beaches during (A) June and (B) July 2010. Response injury categories were as follows: $1=$ manual only, lower frequency $(<20$ visits/month) and included vehicle traffic and mechanical augering; $2=$ mostly manual but included walk-behind sifters, higher frequency ( $>$ t20 visits/month) and included vehicle traffic; $3=$ treatment at least twice in a month with a mechanical beach groomer that would sift the sand down to a depth of $30 \mathrm{~cm}$, all tilling operations and intensive manual removal; and $4=$ treatment at least twice a month with a mechanical device, and beach sediment was mechanically removed from the beach and sifted at least once a month (Michel et al. 2015)

Fig. 1. Loggerhead nesting beaches in western Florida, including index beaches that were used in this study. To delineate areas affected by the Deepwater Horizon (DWH) oil spill (NW Florida) and the area that was relatively unaffected (SW Florida) for our analysis, we used the maximum eastern extent of the cumulative surface oil footprint (gray area) estimated by remote sensing (i.e. synthetic aperture radar) and oiled shoreline observations (orange shoreline extent) recorded by shoreline cleanup and assessment technique (SCAT) surveys. Both synthetic aperture radar (SAR) and SCAT datasets were downloaded from NOAA's Environmental Response Management Application (ERMA 2015)

We examined records of loggerhead nesting at 3 index beaches in NW Florida that are part of the Northern GoM Recovery Unit (Santa Rosa Island, Panama City, and St. Joseph Peninsula State Park) as well as at 3 index beaches in SW Florida that are part of the Peninsular Florida Recovery Unit (Sanibel Island, Delnor-Wiggins Pass State Park, and Keewaydin Island; Table 1, Fig. 1). Using the procedure of Witherington et al. (2009), we aggregated the nest counts that were initially recorded daily in each beach zone into annual beach totals before conducting 
Table 1. Attributes of loggerhead index beaches in northwest Florida (NW FL) and southwest Florida (SW FL)used as the basis of statistical analyses of nest densities, and adjacent nesting beaches to which results were applied. Note: Totals may not sum due to rounding

\begin{tabular}{|llcccccc|}
\hline $\begin{array}{l}\text { Coast } \\
\text { region }\end{array}$ & Index beach & $\begin{array}{c}\text { Number } \\
\text { of zones }\end{array}$ & $\begin{array}{c}\text { Average } \\
\text { zone length } \\
(\mathrm{m})\end{array}$ & $\begin{array}{c}\text { Range } \\
(\mathrm{m})\end{array}$ & $\begin{array}{c}\text { Index beach } \\
\text { total length } \\
(\mathrm{km})\end{array}$ & $\begin{array}{c}\text { Adjacent } \\
\text { beaches total } \\
\text { length }(\mathrm{km})\end{array}$ & $\begin{array}{c}\text { Total } \\
\text { length } \\
(\mathrm{km})\end{array}$ \\
\hline NW FL & & & & & \\
& Panama City & 35 & 807 & $591-1044$ & 28.2 & 56.3 & 84.6 \\
& Santa Rosa Island & 27 & 777 & $671-965$ & 21.0 & 98.0 & 119.0 \\
& St. Joseph Peninsula State Park & 36 & 417 & $165-616$ & 15.0 & 159.3 & 174.3 \\
& Region total & 98 & 655 & $165-1044$ & 64.2 & 313.6 & 377.9 \\
SW FL & Keewaydin Island & 9 & 776 & $258-980$ & 7.0 & 64.2 & 71.2 \\
& Sanibel Island & 6 & 1428 & $602-2077$ & 8.6 & 241.7 & 250.3 \\
& Delnor-Wiggins Pass State Park & 8 & 983 & $474-1559$ & 7.9 & 28.8 & 36.6 \\
& Region total & 23 & 1018 & $258-2077$ & 23.5 & 334.7 & 358.1 \\
Grand total & 121 & 724 & $165-2077$ & 87.7 & 648.3 & 736.0 \\
\hline
\end{tabular}

our regression modeling. The aggregation procedure converted daily zone-level counts into total counts within 8 2-wk-long periods to account for internesting periods for loggerheads (Conant et al. 2009). We divided the first $98 \mathrm{~d}$ of the season into seven 14-d periods, and the final period consisted of $11 \mathrm{~d}$. When daily counts were not recorded, counts for those days were assumed to equal the average number of nest counts observed in that zone on all other days within the same biweekly period.

A different imputation method was required in cases where data were completely absent for a particular zone and period. For the 6 index beaches from 1997 to 2012, data were completely absent only for Period 8 of 2004 at Sanibel Island. We imputed the missing count data by assigning zone-level count values equal to the average zone-level counts recorded there for 2001-2003 and 2006-2008. Although the data imputation method we employed for Period 8 of 2004 at Sanibel Island differed from the imputation method of Witherington et al. (2009), using a simpler imputation method was appropriate for our dataset because the typical nesting rates in Period 8 at Sanibel Island were near zero, and the practical effect of these data imputations on subsequent statistical analysis was negligible. Annual total nest counts for an index beach were defined as the sum of all zone-level counts for all 8 periods.

Annual total nest counts per kilometer at the 6 index beaches from 1997 to 2012 (Fig. 3) were the basis of regression modeling. Santa Rosa Island, Panama City, and St. Joseph Peninsula State Park were assigned to the 'NW Florida' region that was subject to oil effects in 2010, while Sanibel Island, Delnor-Wiggins Pass State Park, and Keewaydin Island were assigned to the 'SW Florida' region that was not likely subject to oil impacts. This model construction allowed us to explicitly test for significant differences in nesting on NW and SW Florida beaches in 2010 .

\section{Before-after-control-impact statistical model}

The eastern extent of the offshore oil slick described by the cumulative surface oil footprint detected by synthetic aperture radar (SAR), the shoreline oiling recorded
Fig. 3. Empirical records of annual nest densities at 6 index beaches, 3 in NW Florida (open symbols) and 3 in SW Florida (filled symbols). See Fig. 1 for locations of beaches 
in shoreline cleanup and assessment technique (SCAT) surveys, and the shoreline cleanup activities (Michel et al. 2015) only extended to approximately $30 \mathrm{~km}$ east of St. Joseph Peninsula (Fig. 1). Beach cleanup activities occurred on the 3 index beaches in NW Florida during the peak of the nesting season (June and July). All 3 index beaches had at least a Response Injury (RI) category of 1 (manual only, lower frequency $[<20$ visits per month], and included vehicle traffic and mechanical augering) in June with one $3.2-\mathrm{km}$ (2.0-mile) segment with an RI score of 4 (treatment at least twice a month with a mechanical device, and sediment was mechanically removed from the beach and sifted at least once a month beach; mechanical removal of clean sediments for manual removal of oiled sediments). In July, the RI values on these 3 index beaches were 2 (mostly manual but included walk-behind sifters, higher frequency [>20 visits per month] and included vehicle traffic) with some segments scoring 3 (treatment at least twice a month with a mechanical beach groomer that would sift the sand down to a depth of $30 \mathrm{~cm}$, all tilling operations and intensive manual removal) (Michel et al. 2015). This beach disturbance occurred during the loggerhead nesting season.

Loggerheads nesting on beaches in SW Florida were relatively unaffected by the DWH spill (SAR and SCAT datasets accessed through the NOAA Environmental Response and Management Application) (ERMA 2015) (Fig. 1). We used an indirect approach to quantify reduction in nesting by estimating the difference between actual and expected loggerhead nesting rates on beaches that were within the DWH footprint, in NW Florida, and beaches that were outside of the DWH shoreline cleanup activity footprint, in SW Florida. Our hypothesis was that loggerhead nesting in oiled areas of NW Florida may have been subjected to negative effects in 2010, while loggerhead nesting on the unoiled coast of SW Florida would not have been subject to such effects.

To test our hypothesis, we followed a before-aftercontrol-impact (BACI) statistical modeling procedure (Stewart-Oaten \& Bence 2001), as initially described in Cacela \& Dixon (2013). The BACI model construct included 2 important assumptions. The first assumption was that general biological conditions that govern patterns of nesting abundance in the 2 areas would lead to a consistent statistical relationship in nesting rates in the 2 areas that could be used to detect differences caused by unique effects in one area or one year. Although loggerheads that nest in the GoM belong to 2 different recovery units (NMFS \&
USFWS 2011, Shamblin et al. 2011, 2012), post-nesting loggerheads from these recovery units use similar residence areas during and after the nesting season throughout the GoM (Hart et al. 2012, 2013, Foley et al. 2014, Hardy et al. 2014) and demonstrate site fidelity to residence areas (Tucker et al. 2014). Thus, broad-scale environmental conditions (e.g. ocean temperatures) that affect sea turtle nesting phenology within and across years (Hawkes et al. 2007, Chaloupka et al. 2008, Weishampel et al. 2010, Lamont \& Fujisaki 2014) should affect these recovery units similarly.

The second assumption was that an effect that reduced 2010 nesting rates exclusively in NW Florida could be identified by comparing proportional changes in the number of nests within and between regions. In other words, we assumed that if there was a significant DWH effect on nesting in NW Florida during 2010, it could be identified by the interaction coefficient for the NW Florida region in 2010 in a model for the log-transformed mean number of nests. The use of proportional changes and log-transformed mean is appropriate for these data when the typical annual numbers of nests per kilometer of beach ranges from $<1$ nest $\mathrm{km}^{-1}$ (Santa Rosa Island) to nearly 31 nests $\mathrm{km}^{-1}$ (Delnor-Wiggins Pass State Park). Because we used data from multiple beaches and multiple years, our analysis did not require that the trends in the 2 regions be exactly parallel if there were no NW Florida effects in 2010. Our statistical model included a term for random variation specific to each beach and year. Discrepancies from parallel trends on each beach would increase the variance of this random effect and would make it harder to identify an effect specific to one year and area. Therefore, observed nest counts would have to deviate significantly from expected for a specific year-area effect to be detectable by our model.

The goal of the analysis is relatively simple: a comparison of nesting on NW Florida index beaches in 2010 with the extrapolation of data from SW Florida and other years. However, doing so carefully requires a statistical model that accounts for multiple sources of variability, including variability between beaches, variability between years, and variation due to a 2- or 3-yr remigration interval (McDonald et al. 2000). We used a generalized linear mixed model (Eqs. 1-11) to estimate the degree to which observed 2010 nesting rates in NW Florida differed from expected nesting rates. The basic structure of the model was an over-dispersed, quasi-Poisson model with an offset term for the length of the beach. Additional random effects in the model allowed variation be- 
tween beaches, variations between years, and an observation-specific random effect. The role of these equations is described below.

$$
\begin{aligned}
& \tau_{i j k l}=\mu_{i j}+\alpha_{i k}+\beta_{j l}+\alpha \beta_{i j k l} \\
& \alpha_{i k} \sim N\left(0, \sigma_{\text {beach }}^{2}\right) \\
& \beta_{j 1} \sim N\left(0, \sigma_{\text {year }}^{2}\right) \\
& \alpha \beta_{i j k l} \sim N\left(0, \sigma_{\text {obs }}^{2}\right) \\
& \mathrm{E}\left(Y_{i j k l} \mid \alpha_{i k}, \beta_{j l}, \alpha \beta_{i j k l}\right)=m_{i k} \times \mathrm{e}^{\tau_{i j k l}} \\
& \operatorname{Var}\left(Y_{i j k l} \mid \alpha_{i k}, \beta_{j l}, \alpha \beta_{i j k l}\right)=\varphi \times m_{i k} \times \mathrm{e}^{\tau_{i j k l}} \\
& \operatorname{Cov}\left(Y_{i j k l}, Y_{i j k l^{\prime}}, l-l^{\prime}=1 \mid \alpha_{i k}, \beta_{j l}, \alpha \beta_{i j k l}\right) \\
& =\varphi_{1} \times m_{i k} \times \sqrt{\mathrm{e}^{\tau_{i j k l}} \mathrm{e}^{\tau_{i j k l^{\prime}}}} \\
& \operatorname{Cov}\left(Y_{i j k l}, Y_{i j k l^{\prime}}, l-l^{\prime}=2 \mid \alpha_{i k}, \beta_{j l}, \alpha \beta_{i j k l}\right) \\
& =\varphi_{2} \times m_{i k} \times \sqrt{\mathrm{e}^{\tau_{i j k l}} \mathrm{e}^{\tau_{i j k l}}} \\
& \operatorname{Cov}\left(Y_{i j k l}, Y_{i j k l^{\prime}}, l-l^{\prime}=3 \mid \alpha_{i k}, \beta_{j l}, \alpha \beta_{i j k l}\right) \\
& =\varphi_{3} \times m_{i k} \times \sqrt{\mathrm{e}^{\tau_{i j k l}} \mathrm{e}^{\tau_{i j k l^{\prime}}}} \\
& \operatorname{Cov}\left(Y_{i j k l}, Y_{i j k l^{\prime}}, 1-l^{\prime}=4 \mid \alpha_{i k}, \beta_{j l}, \alpha \beta_{i j k l}\right) \\
& =\varphi_{4} \times m_{i k} \times \sqrt{\mathrm{e}^{\tau_{i j k l}} \mathrm{e}^{\tau_{i j k l^{\prime}}}} \\
& \operatorname{Cov}\left(Y_{i j k l}, Y_{i j k l^{\prime},} l-l^{\prime}>4 \mid \alpha_{i k}, \beta_{j l}, \alpha \beta_{i j k l}\right)=0
\end{aligned}
$$

where $i$ is the type of beach $(i=1$, SW Florida; 2 , NW Florida); $j$ is the type of year ( $j=1$, impact year, 2010 ; 2 , other years); $k$ is a specific beach within a type of beach $(k=1,2,3) ; l$ is a specific year within a type of year $(l=1 \ldots 15$ for non-impact years, $l=1$ for 2010$) ; \mu_{i j}$ is the fixed effect mean (log scale) for beach type $i$ in year type $j_{i} \alpha_{i k}$ is the random effect of beach $k$ of type $i_{i} \beta_{j l}$ is the random effect of year 1 of year type $j_{i} \alpha \beta_{i j k l}$ is the random effect of beach-year $k l$, of type $i j$, i.e. a single observation; $\varphi_{i}$ is the covariance of annual lag of $i$ years where $i \in\{1,2,3,4\}_{i}, m_{i k}$ is the length of beach $k$ of type $i$, in $\mathrm{km} ; Y_{i j k l}$ is the number of nests in beach $k$ of type $i$ in the year $l$ of type $j_{\text {; }} E$ is expected value; Var is variance; and Cov is covariance.

Eq. (1) describes the log-transformed mean number of nests per kilometer for beach $k$ of type $i$ in year 1 of type $j$. This has 4 components: the mean for type of beach and type of year, a beach-specific deviation for each beach within its type, a year-specific deviation for each year within its type, and an observationspecific random effect for each combination of beach and year. The beach-specific deviations (Eq. 2) are a random effect with a variance $\sigma_{\text {beach }}^{2}$ that will be estimated. This random effect allows the nest counts for each beach within a region to differ. Analogously, the year-specific deviations (Eq. 3) allow for 'good' or 'bad' nesting years that are consistent for all 6 index beaches. The observation-specific random effect (Eq. 4) allows for 'good' or 'bad' nesting years that are specific to an individual beach. The predicted nest count for each beach and year (Eq. 5) is the beach length, $m_{i k}$, times the back-transformed prediction for that beach and year. The variance of the nest count (Eq. 6) is proportional to the mean. Both the proportionality constant (Eq. 6) and the observation-specific random effect (Eq. 4) allow nest counts to be over-dispersed relative to a Poisson distribution, having a variance that is larger than the mean.

The remaining equations allow for temporal autocorrelation within beaches, which is plausible because individual NWA loggerheads typically exhibit 2- or 3-yr remigration intervals between consecutive nesting events (Conant et al. 2009, Hays et al. 2010). Because remigration intervals vary within and among individuals, we included autocorrelation terms that could capture remigration intervals ranging from 1 to $4 \mathrm{yr}$ in the model. Eq. (7) represents the covariance between 2 observations on the same beach separated by 1 yr. Similarly, Eqs. (8) to (10) represent the covariance for observations separated by 2,3 , or $4 \mathrm{yr}$, respectively, and the covariance for autocorrelation with a lag of 4 or more years was defined to be zero (Eq. 11). Parameters in the model were estimated using SAS Proc Glimmix, version 9.3.

\section{RESULTS}

Between 1997 and 2009, the average total number of loggerhead nests at the 3 index beaches in NW Florida included in the present analyses was 142. In 2010 , only 72 nests were recorded; this was the lowest total in the study period (Fig. 4). In comparison, the 3 index beaches in SW Florida had an average total of 302 nests between 1997 and 2009, and 294 nests in 2010. Nests on the 3 index beaches in NW Florida accounted for approximately $0.33 \%$ of all nests counted on all Florida index nesting beaches statewide, on average, between 1997 and 2009; in 2010, this proportion was $0.15 \%$ (Fig. 4). Thus, loggerhead nesting on the 3 index beaches in NW Florida in 2010 deviated from the expected trends.

The BACI model confirmed that loggerhead nest densities in 2010 in NW Florida were below the expected densities derived from the model; the value of 


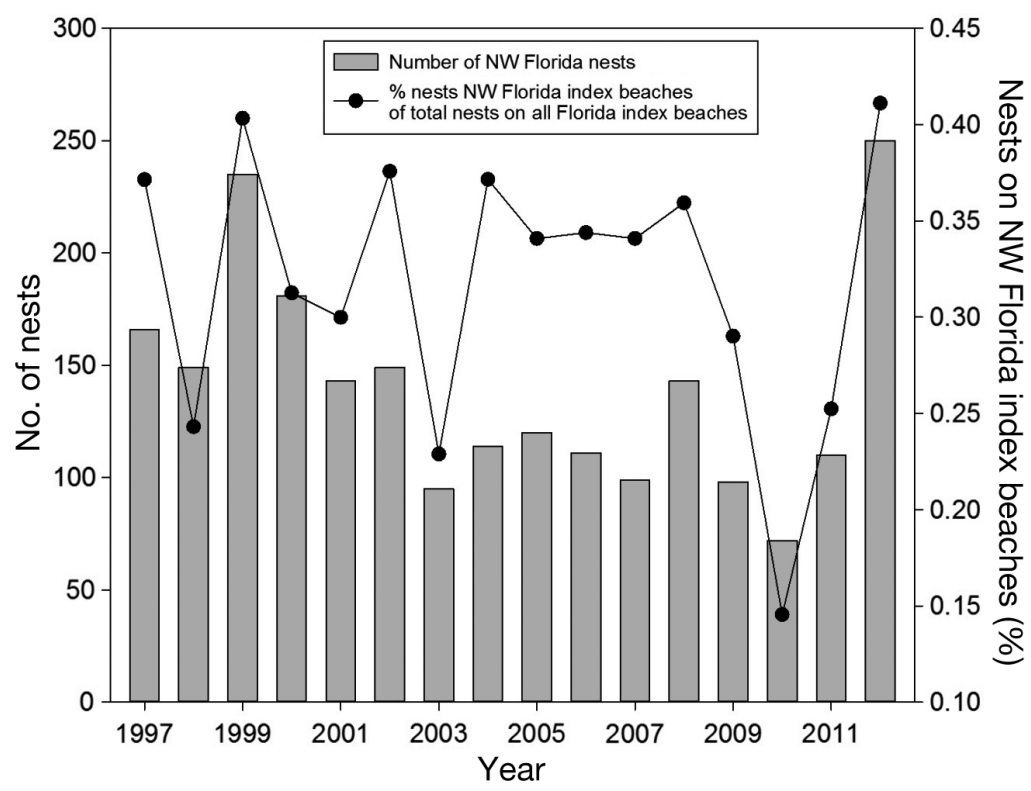

Fig. 4. Total annual nest counts of loggerhead turtles on 3 index beaches in NW Florida and the percentage that these represent of total annual nest counts on all index beaches in Florida (1997-2012) to decline relative to expected nest densities, and that the magnitude of that reduction was greater than would be expected as a result of random variation from geographic and temporal factors.

We quantified the difference between expected and actual 2010 nest densities in both regions by first assuming that the region $\times$ impact year interaction term was equal to zero, and then by using the statistically significant non-zero interaction term (Fig. 5). If the interaction term was zero, which assumed the absence of a unique effect of the region or of the year 2010, the expected nest density estimate was 1.52 nests $\mathrm{km}^{-1}$. In contrast, using the non-zero interaction term, which indicated a significant effect of the region and of the year 2010, the modeled median nest density estimate was 0.857 nests $\mathrm{km}^{-1}$.

the interaction term was statistically different from zero $(p<0.018$; Table 2$)$. The contrast for the BACIeffect interaction term demonstrated that the 2010 estimated median nest density in NW Florida was $56.3 \%$ (95\% confidence interval [CI]: 35.2-90.1\%) of the expected rate, a reduction of $43.7 \%$ (95\% CI: 9.9-64.8\%; Table 3). These results indicated that some factor caused 2010 nest densities in NW Florida

Table 2. Type III tests of fixed effects

\begin{tabular}{|lcccc|}
\hline Effect & $\begin{array}{c}\mathrm{df} \\
\text { (numerator) }\end{array}$ & $\begin{array}{c}\mathrm{df} \\
\text { (denominator) }\end{array}$ & & \\
\hline Impact year & 1 & 14 & 1.19 & 0.2928 \\
Coast segment & 1 & 4 & 5.56 & 0.0778 \\
Impact year $\times$ coast segment & 1 & 74 & 5.93 & 0.0173 \\
\hline
\end{tabular}

Thus, the estimated number of absent nests in 2010 was the difference between these values, or 0.663 nests $\mathrm{km}^{-1}$ (95\% CI: 0.15-0.98 nests km ${ }^{-1}$ ).

Although the modeling was based on data collected at index beaches only, it is useful to express the findings in terms of a broader geographic scope and of total 'absent' nests, in addition to simply a reduction percentage. To do this, we assumed that the factors affecting nest densities among index beaches are practically the same as those affecting adjacent non-index beaches in NW Florida. The 3 index beaches in NW Florida comprise $64.2 \mathrm{~km}$ of coastline, while there is $377.9 \mathrm{~km}$ of coastline suitable for nesting in NW Florida (Table 1). By applying the reduced nest density estimate of 0.663 nests $\mathrm{km}^{-1}$ to this additional nesting habitat outside of index nesting beaches, approximately 251 nests were 'absent' from

Table 3. Modeled estimates of nesting rates (nests $\mathrm{km}^{-1}$ ) by impact status and coastline segment, and estimated interaction indicating the magnitude of the before-after-control-impact (BACI) effect that quantifies the modeled deviation from expected nesting rates among northwest Florida (NW FL) beaches in 2010. Estimated fractional nesting rate is among NW FL beaches relative to expected nesting rates. (-): not applicable

\begin{tabular}{|c|c|c|c|c|c|c|}
\hline Category of estimated quantity & $\begin{array}{c}\text { Estimate } \\
\text { of log } \\
\text { (nests } \mathrm{km}^{-1} \text { ) }\end{array}$ & $\begin{array}{l}\text { Estimated frac- } \\
\text { tional nesting rate } \\
{[\log (\text { fraction})]}\end{array}$ & $\mathrm{SE}$ & $95 \% \mathrm{CI}$ & $\begin{array}{l}\text { Median fraction } \\
\text { of expected nesting } \\
\text { rate (nests } \mathrm{km}^{-1} \text { ) }\end{array}$ & $\begin{array}{c}95 \% \mathrm{CI} \text { on } \\
\text { median }\end{array}$ \\
\hline NW FL, any year except 2010 & 0.418 & - & 0.664 & $(-0.905,1.741)$ & - & - \\
\hline NW FL, year 2010 effect & -0.195 & - & 0.736 & $(-1.661,1.270)$ & - & - \\
\hline Southwest coast, any year except 2010 & 2.346 & - & 0.663 & $(1.025,3.668)$ & - & - \\
\hline Southwest coast, year 2010 effect & 2.307 & - & 0.722 & $(0.868,3.746)$ & - & - \\
\hline Interaction contrast (BACI effect) & - & $-0.574(\mathrm{p}<0.018)$ & 0.236 & $(-1.043,-0.104)$ & 0.563 & $(0.352,0.901)$ \\
\hline
\end{tabular}




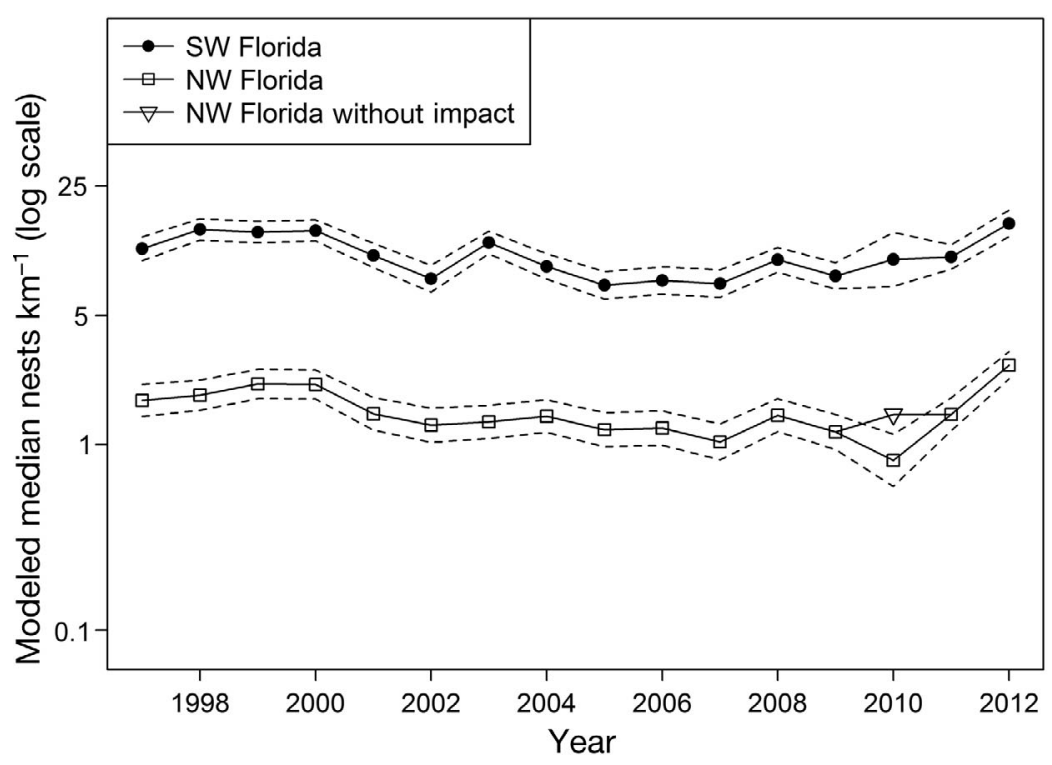

Fig. 5. Modeled values of annual nest densities (nests per $\mathrm{km}$ ) on index beaches in SW Florida (filled circles) and NW Florida (open squares), and the modeled estimate of the NW Florida nest density (open triangle) in the hypothetical absence of the 2010 year effect. Dashed lines indicate the $95 \%$ CI on the modeled median value

NW Florida beaches in 2010. This estimate is negatively biased because it does not quantify additional reduction in nest density on all other beaches on which loggerheads from the Northern GoM Recovery Unit nest.

\section{DISCUSSION}

Loggerhead nest densities were reduced by $43.7 \%$ on 3 NW Florida index beaches in 2010 compared with previous and subsequent years at those beaches and based on trends on beaches in SW Florida, outside the affected area (Figs. $2 \& 3$ ). This reduction was of a greater magnitude than would be expected based on random variation in geographic and temporal effects. Therefore, we conclude that one or more unusual phenomena caused lower-than-expected nest density on NW Florida beaches in 2010.

DWH oil entered nearshore areas and washed onto beaches along the northern GoM shoreline during the summer of 2010, requiring extensive, disruptive activities to remove contaminated beach sand, oil, and debris (DWH NRDA Trustees 2016). Among areas that support loggerhead turtle nesting and hatchling dispersal, these factors were present in NW Florida in 2010, but absent from SW Florida nesting sites (Michel et al. 2015). Therefore, we conclude that the estimated reduction in nest densities was because of indirect (e.g. disturbance) and direct (e.g. mortality) effects related to the DWH incident.

The DWH spill effect likely to have had the greatest influence on sea turtle nesting was the profound level of disturbance resulting from response activities in nearshore areas and on nesting beaches (Fig. 2). During the DWH response, intensive boat activity and the presence of physical barriers (e.g. booms) in nearshore waters (DWH NRDA Trustees 2016) that occurred during the nesting season could have prevented female loggerheads from accessing the beach. On NW Florida nesting beaches, crews were frequently performing manual and mechanized removal of contaminated sand and debris, including surface removal by shovels, rakes, and other hand tools to $15 \mathrm{~cm}$ below the sand surface; removal of oiled sediments that were more than $15 \mathrm{~cm}$ deep, often using heavy machinery and vehicles to mechanically remove the clean overburden; vehicular traffic for transport of workers and waste; mechanical augering; and removal of submerged oil mats (Michel et al. 2015). These types of activities, particularly when they occur at night using artificial lights, are known to deter gravid turtles from coming ashore to lay eggs (Witherington et al. 2014, NMFS \& USFWS 2008, Conant et al. 2009, Michel et al. 2015). Wildlife response workers documented several direct observations of disturbance and deterrence of female loggerheads attempting to nest on NW Florida beaches (Lauritsen et al. 2012).

In addition to the disturbance caused by response activities, the DWH NRDA documented mortality among all life stages for multiple sea turtle species, including adult loggerheads, caused by adverse effects of oil exposure, as well as response activities at sea, including relocation trawling, dredging, and collisions with response vessels (DWH NRDA Trustees 2016). It is possible that mortality of reproductive females at sea caused by DWH oil or response activities contributed to the observed reduction in nesting, although we did not quantify the actual extent to which adult female loggerhead mortality contributed to the low nest densities in 2010. Nesting increased again in 2011 and 2012 in both regions (Figs. 3 \& 4), which suggests that some turtles that avoided mortality may have deferred nesting until subsequent 
years when the presence of oil and oil spill response activities in and around nesting beaches were reduced or non-existent (Michel et al. 2015). Analyses of potential changes in remigration intervals among nesting loggerheads in the Northern GoM Recovery Unit in the years since the DWH spill are necessary to elucidate this effect. Although the observed decline in nest densities might not have been the result of widespread mortality, a loss of 251 nests represents a reduction of approximately $36 \%$ in the expected output in 2010 for the relatively small Northern GoM Recovery Unit in Florida. Continual, consistent nest monitoring is needed to evaluate possible long-term negative consequences to the population. Nonetheless, injuries as defined under the Oil Pollution Act do not have to have estimated or demonstrable population-level effects. Therefore, deferred or unrealized loggerhead reproduction in 2010 that is attributable to the DWH spill qualifies as injury under the NRDA framework and must be considered in restoration planning (DWH NRDA Trustees 2016).

The presence of oil in nearshore areas adjacent to nesting beaches in 2010 might have interfered with the chemosensory capabilities of nesting loggerheads. Adult turtles are thought to use chemosensory cues to recognize beaches in their natal region, once other navigational mechanisms have allowed them to travel longer distances to arrive in the vicinity of their destination (Carr et al. 1978, Lohmann et al. 1997, Southwood \& Avens 2010). Although there were no direct observations of oil adversely affecting the homing behavior of nesting loggerheads, oil in the water near nesting beaches might have interfered with chemosensory mechanisms that turtles rely on to find their nesting beaches in NW Florida, thus preventing them from nesting.

We also considered alternative explanations of the observed reduction. Shoreline cleanup activities could have obscured turtle crawls, causing nests to be inadvertently missed or misidentified as false crawls during daily patrols (Lauritsen et al. 2012), which would represent an unquantifiable bias in the original dataset. It is also possible that gravid loggerhead turtles that were deterred from nesting on beaches with ongoing response activities might have nested instead at adjacent or nearby beaches with no response activities. However, adjacent beaches along the northern GoM shoreline west of the Florida Panhandle in Alabama were also subject to active response activities during the DWH spill and cleanup efforts (Michel et al. 2015), and showed similar decreases in loggerhead nest densities (Frater 2015). This suggests that the 2010 reduction in turtle nesting at NW Florida index beaches was the result not of nesting turtles switching to alternate nesting locations, but rather of the reduced nesting output of these turtles in 2010.

Another possible explanation for the reduction in nest density was that environmental conditions in foraging areas could have affected loggerhead nesting phenology in 2010. Lamont \& Fujisaki (2014) showed that sea surface temperatures (SSTs) in the northern GoM during February through April 2010 were among the coldest on record since 1996, and they demonstrated that colder spring SSTs were significantly associated with the later onset of seasonal nesting and lower nest abundance in the northern GoM, presumably because cold ambient temperatures delayed or constrained the ability of ectothermic sea turtles to reach breeding condition (Hawkes et al. 2007, Chaloupka et al. 2008, Weishampel et al. 2010). Considering well-documented overlap between turtles from NW Florida and SW Florida on foraging areas in the northern and eastern GoM (Hart et al. 2012, 2013, Foley et al. 2014, Hardy et al. 2014, Tucker et al. 2014), significant environmental influences in the GoM might have caused delayed or reduced nesting abundance on beaches along the NW Florida coastline. However, the reduced nest densities on NW Florida beaches were not reflected on SW Florida beaches (Fig. 5), which suggests that the cold spring SSTs in 2010 were not likely to have caused the regional discrepancy in nest densities. Because our analysis was designed specifically to highlight a significant interaction between year (2010) and nest densities on beaches in NW Florida and on SW Florida beaches, we cannot exclude the possible influence of cold spring SSTs on loggerhead nesting phenology in NW Florida in 2010. Nonetheless, because the trends in nest densities between the 2 regions were similar before and after 2010 (Fig. 5), and because the presence of oil and associated cleanup operations was unique to NW Florida beaches, particularly in the summer of 2010, the most parsimonious explanation for the observed reduction in nest densities on NW Florida beaches was adverse effects from the DWH oil spill and response activities.

The loss of 251 nests in 2010, presumably due to the DWH spill, represents approximately $36 \%$ of the reproductive output for the NGoM Recovery Unit for 2010. Nesting for this Recovery Unit has been monitored consistently since 2010; currently there is no significant trend in loggerhead nesting (http:// myfwc.com/research/wildlife/sea-turtles/nesting/ beach-survey-totals/). Further research and nesting season monitoring are needed to evaluate whether 
this reduced nesting in 2010 will have long-term impacts on the population. Under the DWH NRDA, this unrealized reproductive output caused by DWH was included in quantification of the full extent of injuries to sea turtles, and was accounted for in restoration planning to address those losses (DWH NRDA Trustees 2016).

Author contributions. This manuscript represents the combination of two complementary but separate initiatives to assess possible effects of DWH on loggerhead nesting in the northern GoM. A.M.L. recognized potential effects of DWH on loggerhead nesting in the northern GoM, and initiated and led efforts to assess the possible reduction in loggerhead nesting in NW Florida related to the DWH incident. A.M., B.E.W., B.B., R.H., and S.L.M. managed and analyzed relevant nesting data to more closely examine nesting trends among nesting beaches that could be related to the DWH oil spill and associated response activities. A.M.L., A.M., B.E.W., B.B., R.H., and S.L.M. prepared the Lauritsen et al. (2012) Opinion Paper that initially described the significant decline in nesting in NW Florida and observations of disturbance from response activities that supported the conclusion that estimated reductions were caused by the DWH oil spill and response activities. P.M.D. and D.C. conceived of and performed the BACI analysis that provided statistical description of and support for the initial hypothesis that loggerhead nest densities in NW Florida were significantly lower in 2010 than expected. B.P.W. assisted in combining the two products and providing biological and DWH NRDA context. All authors wrote the manuscript.

Acknowledgements. This work was part of the DWH NRDA being conducted cooperatively among the US Fish and Wildlife Service, NOAA, other federal and state Trustees, and BP PLC. The Florida Fish and Wildlife Conservation Commission's Fish and Wildlife Research Institute was responsible for the Index Nesting Beach Survey program that collected the original data on nesting rates. For collecting the data, we gratefully acknowledge the following INBS participants: St. Andrew Bay Resource Management Association (Panama City Beach), Eglin Air Force Base (Santa Rosa), St. Joseph Peninsula State Park (St. Joseph Peninsula), the Conservancy of Southwest Florida (Keewaydin Island), the Sanibel-Captiva Conservation Foundation (Sanibel Island), and the Collier County Parks \& Recreation Department and Delnor-Wiggins Pass State Park (Delnor-Wiggins State Park). Funding for Florida's sea turtle nest programs has come from the US Fish and Wildlife Service and from the Florida Sea Turtle Protection Trust Fund. We also acknowledge RPI, Inc., for information about response activities. The findings and conclusions in this article are those of the authors and do not necessarily represent the views of the US Fish and Wildlife Service.

\section{LITERATURE CITED}

Cacela D, Dixon PM (2013) A statistical analysis of loggerhead turtle (Caretta caretta) nesting rates in western Florida, 1997-2012. DWH Sea Turtles NRDA Technical
Workshop Report. https://pub-dwhdatadiver.orr.noaa.gov/ dwh-ar-documents/894/DWH-AR0096905.pdf (accessed 25 Jan 2017)

Carr A, Carr MH, Meylan AB (1978) The ecology and migrations of sea turtles, 7 . The west Caribbean green turtle colony. Bull Am Mus Nat Hist 162:1-46

* Chaloupka M, Kamezaki N, Limpus C (2008) Is climate change affecting the population dynamics of the endangered Pacific loggerhead sea turtle? J Exp Mar Biol Ecol 356:136-143

Conant TA, Dutton PH, Eguchi T, Epperly SP and others (2009) Loggerhead sea turtle (Caretta caretta) 2009 status review under the U.S. Endangered Species Act. Report of the Loggerhead Biological Review Team to the National Marine Fisheries Service, August 2009. www. nmfs.noaa.gov/pr/pdfs/statusreviews/loggerheadturtle 2009.pdf (accessed 25 Jan 2017)

* DWH NRDA (Deepwater Horizon Natural Resource Damage Assessment) Trustees (2016) Deepwater Horizon oil spill programmatic damage assessment and restoration plan and programmatic environmental impact statement. www.gulfspillrestoration.noaa.gov/sites/default/files/wpcontent/uploads/Front-Matter-and-Chapter-1_Introductionand-Executive-Summary_508.pdf (accessed 25 Jan 2017)

* ERMA (Environmental Response and Management Application) (2015) Web application: Deepwater Gulf Response. Environmental Response Management Application, National Oceanic and Atmospheric Administration, Seattle, WA. http://gomex.erma.noaa.gov/erma.html (accessed 7 Jan 2016) (accessed 25 Jan 2017)

Foley AM, Schroeder BA, Hardy R, MacPherson SL, Nicholas $M$ (2014) Long-term behavior at foraging sites of adult female loggerhead sea turtles (Caretta caretta) from three Florida rookeries. Mar Biol 161:1251-1262

* Frater B (2015) Assessing injury to loggerhead sea turtles in Alabama. DWH Sea Turtles NRDA Technical Working Group Report. Prepared for the US Fish and Wildlife Service. https://pub-dwhdatadiver.orr.noaa.gov/dwh-ardocuments/894/DWH-AR0063419.pdf (accessed 25 Jan 2017)

Hardy RF, Tucker AD, Foley AM, Schroeder BA, Giove RJ, Meylan AB (2014) Spatiotemporal occurrence of loggerhead turtles (Caretta caretta) on the West Florida Shelf and apparent overlap with a commercial fishery. Can J Fish Aquat Sci 71:1924-1933

*Hart KM, Lamont MM, Fujisaki I, Tucker AD, Carthy RR (2012) Common coastal foraging areas for loggerheads in the Gulf of Mexico: opportunities for marine conservation. Biol Conserv 145:185-194

* Hart KM, Lamont MM, Sartain AR, Fujisaki I, Stephens BS (2013) Movements and habitat-use of loggerhead sea turtles in the northern Gulf of Mexico during the reproductive period. PLOS ONE 8:e66921

*Hawkes LA, Broderick AC, Godfrey MH, Godley BJ (2007) Investigating the potential impacts of climate change on a marine turtle population. Glob Change Biol 13:923-932

*Hays GC, Fossette S, Katselidis KA, Schofield G, Gravenor MB (2010) Breeding periodicity for male sea turtles, operational sex ratios, and implications in the face of climate change. Conserv Biol 24:1636-1643

Lamont MM, Fujisaki I (2014) Effects of ocean temperature on nesting phenology and fecundity of the loggerhead sea turtle (Caretta caretta). J Herpetol 48:98-102

Lauritsen AM, Witherington BE, Meylan AA, Trindell RN, MacPherson SL, Ingram DK, Sablan JM (2012) Deepwater 
Horizon Mississippi Canyon-252 oil spill impacts on sea turtles on the nesting beach during 2010 and 2011 - DOI Position. Draft Natural Resource Damage Assessment Opinion Paper dated 22 March 2012. US Fish and Wildlife Service, Jacksonville, FL

Lohmann KJ, Witherington BE, Lohmann CMF, Salmon M (1997) Orientation, navigation, and natal beach homing in sea turtles. In: Lutz PL, Musick JA (eds) The biology of sea turtles, Vol 1. CRC Press, Boca Raton, FL, p 107-136

McDonald TL, Erickson WP, McDonald LL (2000) Analysis of count data from before-after control-impact studies. J Agric Biol Environ Stat 5:262-279

Michel J, Fegley S, Dahlin J (2015) Deepwater Horizon sand beach injury assessment: technical report. Prepared for US Fish and Wildlife Service, Atlanta, GA

Musick JA, Limpus CJ (1997) Habitat utilization and migration in juvenile sea turtles. In: Lutz PL, Musick JA (eds) The biology of sea turtles, Vol 1. CRC Press, Boca Raton, FL, p 137-164

NMFS (National Marine Fisheries Service), USFWS (US Fish and Wildlife Service) (2008) Recovery plan for the Northwest Atlantic population of the loggerhead sea turtle (Caretta caretta), 2nd rvsn. NMFS, Silver Spring, MD. www. fws.gov/northflorida/SeaTurtles/2008_Recovery_Plan/ 20081231_Final\%20NW\%20Loggerhead\%20Recovery\%20 Plan_signed.pdf (accessed 25 Jan 2017)

NMFS (National Marine Fisheries Service), USFWS (US Fish and Wildlife Service) (2011) Endangered and threatened species; determination of nine distinct population segments of loggerhead sea turtles as endangered or threatened. Fed Regist 76:58868-58952

Shamblin BM, Dodd MG, Bagley DA, Ehrhart LM and oth-

Editorial responsibility: Matthew Godfrey,

Beaufort, North Carolina, USA ers (2011) Genetic structure of the southeastern United States loggerhead turtle nesting aggregation: evidence of additional structure within the peninsular Florida recovery unit. Mar Biol 158:571-587

Shamblin BM, Bolten AB, Bjorndal KA, Dutton PH and others (2012) Expanded mitochondrial control region sequences increase resolution of stock structure among North Atlantic loggerhead turtle rookeries. Mar Ecol Prog Ser 469:145-160

* Southwood A, Avens L (2010) Physiological, behavioral, and ecological aspects of migration in reptiles. J Comp Physiol B 180:1-23

Stewart-Oaten A, Bence JR (2001) Temporal and spatial variation in environmental impact assessment. Ecol Monogr 71:305-339

Tucker AD, MacDonald BD, Seminoff JA (2014) Foraging site fidelity and stable isotope values of loggerhead turtles tracked in the Gulf of Mexico and northwest Caribbean. Mar Ecol Prog Ser 502:267-279

*Weishampel JF, Bagley DA, Ehrhart LM, Weishampel AC (2010) Nesting phenologies of two sympatric sea turtle species related to sea surface temperatures. Endang Species Res 12:41-47

Witherington BE, Martin RE, Trindell RN (2014) Understanding, assessing, and resolving light-pollution problems on sea turtle nesting beaches, revised. Florida Fish and Wildlife Research Institute Tech Rep TR-2. http:// f50006a.eos-intl.net/ELIBSQL12_F50006A_Documents/ TR-2Rev2.pdf (accessed 25 Jan 2017)

*Witherington B, Kublis P, Brost B, Meylan A (2009) Decreasing annual nest counts in a globally important loggerhead sea turtle population. Ecol Appl 19:30-54

Submitted: February 16, 2016; Accepted: November 22, 2016 Proofs received from author(s): January 25, 2017 